\title{
Carcinoma adenóide cístico da traqueia, a propósito de um caso com sobrevida longa
}

\author{
Tracheal Adenoid Cystic Carcinoma: Long Survival Case Report
}

\author{
Reis $\mathrm{M}^{1}$, Martelo $\mathrm{F}^{2}$, Bravio $\mathrm{I}^{2}$, Reis $\mathrm{J}^{2}$ \\ ${ }^{1}$ Serviço de Pneumologia, Hospital Sousa Martins, Guarda, Portugal \\ ${ }^{2}$ Serviço de Cirurgia Cardiotorácica, Hospital de Santa Marta, Centro Hospitalar Lisboa Central, Lisboa, Portugal
}

\begin{abstract}
Resumo
0 carcinoma adenóide cístico da traqueia apresenta um crescimento lento. 0 aparecimento de metástases à distância é mais frequente a nível do pulmão. Descrevemos o caso de um doente do sexo feminino, de 57 anos de idade, com diagnóstico de carcinoma adenóide cístico do terço superior da traqueia. 0 doente foi submetido a ressecção segmentar da traqueia. Respectivamente, seis e doze meses mais tarde, identificou-se uma lesão nodular no lobo inferior de ambos os pulmões, posteriormente ressecada. 0 doente é seguido há 4 anos há 4 anos e não apresenta sinais de recidiva. Palabras clave: Neoplasias de la Tráquea. Procedimientos quirúrgicos pulmonares. Estudio de seguimiento
\end{abstract}

\section{Introdução}

Os tumores primários da traqueia são raros ${ }^{1,2,3,4} .0$ carcinoma adenóide cístico (CAC) da traqueia é o segundo tipo histológico mais frequente, apresenta igual distribuição por ambos os géneros ${ }^{2,3}$ e não se relaciona com a existência de hábitos tabágicos. ${ }^{2}$ Tem origem nas glândulas seromucosas localizadas na camada submucosa da traqueia. ${ }^{3}$ Devido à sintomatologia inespecífica, o diagnóstico habitualmente é tardio ${ }^{1,4,5} .0$ tratamento de eleição é a ressecção cirúrgica ${ }^{1,3,4}$. Apresenta crescimento lento, e tem um elevado potencial de invasão local $^{2,3} \cdot$ A metastização à distância é mais frequentemente a nível pulmonar ${ }^{2,3,4} \mathrm{e}$ a recorrência pode ocorrer, mesmo após um período de tempo prolongado ${ }^{2,3}$. Os tumores ressecáveis apresentam uma boa taxa de sobrevida aos 5 e 10 anos de 75 a $91 \%$ e 76 a $55 \%$ respectivamente ${ }^{1,4}$.

\section{Caso clínico}

Doente do género feminino com 57 anos de idade, não fumadora e sem antecedentes pessoais relevantes.

Apresentava queixas de dispneia, pieira e cansaço com 5 anos de evolução, nunca valorizadas pela doente.

Por agravamento das queixas e aparecimento de estridor, recorreu então ao serviço de urgência. Na laringoscopia foi identificada uma lesão tumoral séssil, de base larga, inserida na parede posterior da traqueia e localizada a cerca de $2,5 \mathrm{~cm}$ das cordas vocais, condicionando redução de $80 \%$ do lúmen da traqueia (Figura $1 \mathrm{~A}$ e $1 \mathrm{~B}$ ). Realizou broncoscopia rígida que possibilitou a execução de biópsias e colocação de prótese traqueal de silicone, garantindo a permeabilização do lúmen.

\begin{abstract}
Tracheal adenoid cystic carcinoma has a slow growth and remote metastasis occurs more frequently to the lung. A case of a 57-year-old female patient, with the diagnosis of adenoid cystic carcinoma on the upper part of the trachea is reported. The patient was submitted to segmental tracheal resection. Six and twelve months later, respectively, a nodular lesion was found in the lower lobe of both lungs and later were resected. The patient has been followed up for 4 years and has no sign of relapse.

Keywords: Traqueal neoplasms. Pulmonary surgical procedures. Follow-up studies.
\end{abstract}

0 resultado anátomo-patológico concluiu tratar-se de um carcinoma adenóide cístico. Em Janeiro de 2011 foi operada, sendo 0 acesso à traqueia obtido por cervicotomia transversal. A traqueia foi isolada com preservação dos nervos recorrentes. Procedeu-se à abertura do seu lúmen extraindo-se a prótese traqueal. Foi colocado através do campo operatório, um tubo traqueal estéril, que se introduziu na porção distal da traqueia, para permitir a ventilação durante 0 procedimento. Excisou-se um segmento de traqueia com $6 \mathrm{~cm}$ de extensão, onde se localizava a base de implantação do tumor, com margens de segurança. Esta porção da traqueia estava localizada entre a cartilagem cricóide e a porção média da traqueia (Figure 2). 0 exame extemporâneo dos dois topos traqueais foi negativo. Realizaram-se de manobras de alívio de tensão dos dois topos da traqueia, tais como 0 abaixamento da laringe e a dissecção romba da face anterior da traqueia distal e dos brônquios principais. Efectuou-se então a anastomose entre a cartilagem cricóide e 0 topo distal da traqueia, com pontos separados de fio monofilamento reabsorvível, passando de novo a ventilação a realizar-se pelo tubo oro-traqueal.

A doente mantem seguimento em consulta de Cirurgia Torácica com controlo imagiológico e endoscópico regular.

Em tomografia computorizada do tórax realizada 6 meses após a cirurgia foi detectado um micronódulo de $7 \mathrm{~mm}$ a nível do segmento apical do lobo inferior esquerdo.

No controlo imagiológico constatou-se um crescimento lento desta lesão. Dezassete meses após a cirurgia do tumor primário, foi submetida a ressecção atípica do nódulo, por 
Figura 1 A. TC do tórax: Lesão tumoral da parede posterior da traqueia.

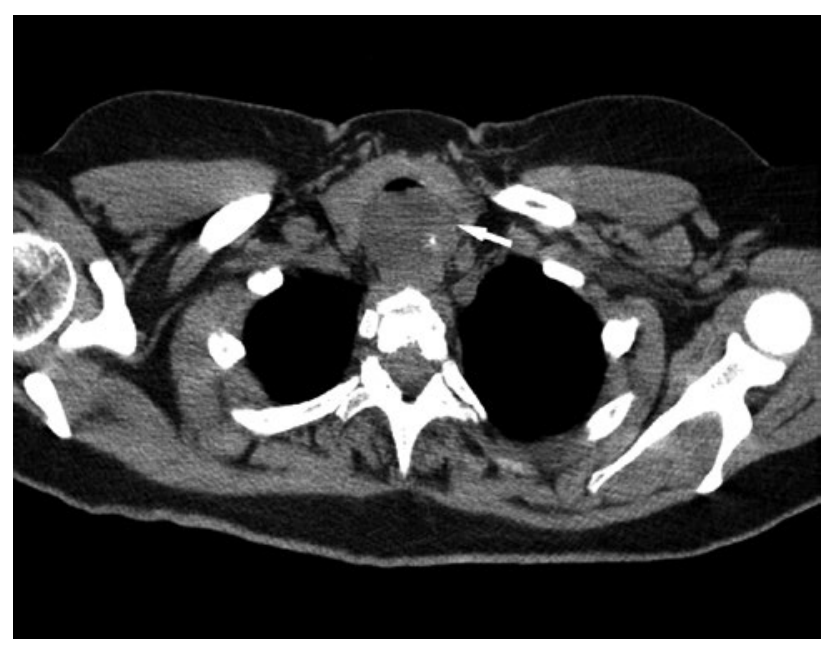

Figura 1 B. Broncoscopia: Lesão tumoral condicionando redução de 80 \% do lúmen da traqueia.

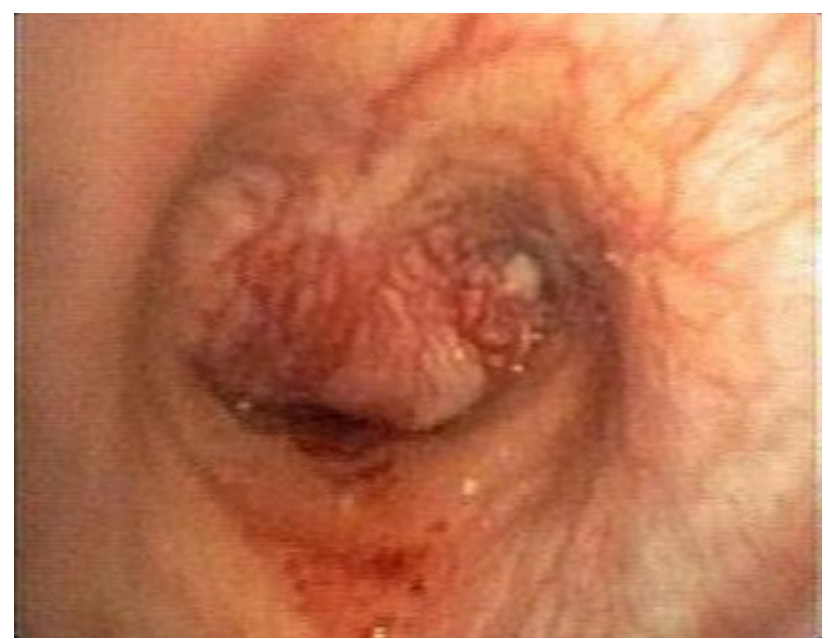

Figura 2. Procedimento cirúrgico: Ressecção segmentar da traqueia.

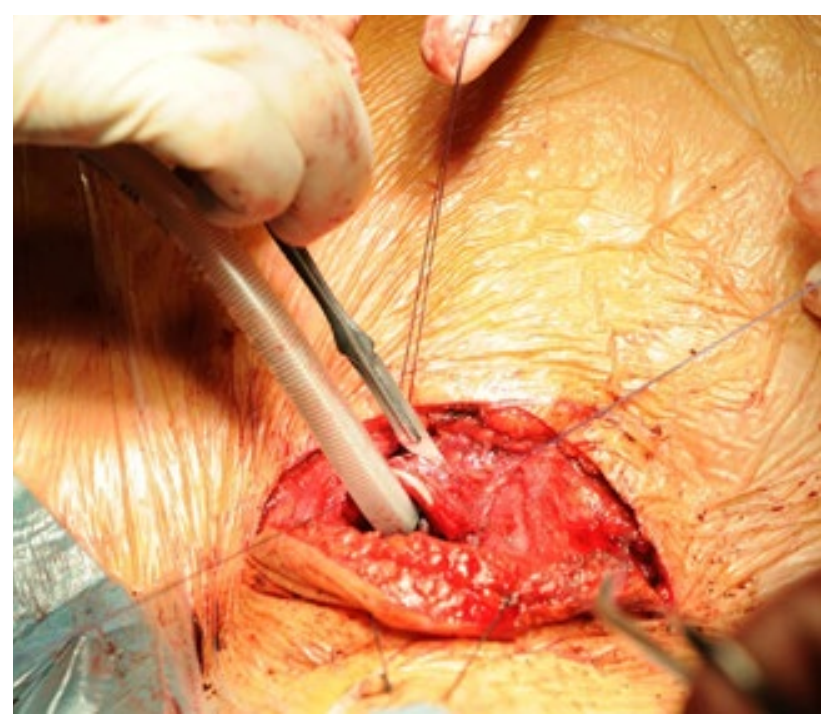

cirurgia minimamente invasiva, Vídeo Assisted Thoracoscopic Surgery (VATS). 0 exame histológico revelou tratar-se de lesão metastática do tumor primitivo.

Do mesmo modo, por crescimento progressivo do nódulo localizado no lobo inferior do pulmão direito, detectado 12 meses após a cirurgia do tumor primitivo, foi submetida em Fevereiro de 2014 a ressecção atípica por VATS, quando este já se apresentava com $12 \mathrm{~mm}$, correspondendo também a lesão metastática do mesmo tumor.

Durante o período de acompanhamento a doente não foi submetida a outro tratamento.

\section{Discussão}

A sintomatologia insidiosa e inespecífica torna o diagnóstico do CAC da traqueia desafiante.

A cirurgia é a terapêutica de eleição, e a indicação para esta terapêutica depende da localização e da extensão da lesão $0^{1,3,4,6}$. Cerca de $25 \%$ dos CAC da traqueia são irressecáveis na altura do diagnóstico ${ }^{1,2,3}$. 0 CAC da traqueia apresenta radiossensibilidade, estando a radioterapia indicada como terapêutica adjuvante, particularmente se houver envolvimento tumoral das margens cirúrgicas ${ }^{3,6}$, assim como nas lesões irressecáveis, podendo ser associada à terapêutica endobrônquica ${ }^{1,2,6}$. Não existem até ao momento esquemas de quimioterapia aprovados no tratamento primário do CAC da traqueia ou perante a evidência de metastização do mesmo². 0 CAC da traqueia apresenta um crescimento lento ${ }^{4}$. Perante ressecção completa pode haver uma recidiva da lesão tumoral a nível local ou metastização loco-regional ou à distância². Se surgir metastização pulmonar está indicada a ressecção cirúrgica da lesão, que permite um aumento da sobrevida ${ }^{3}$, embora nestes casos o prognóstico seja geralmente reservado $0^{2,3}$.

Em conclusão dado o crescimento tumoral lento, o potencial de metastização e 0 aumento da sobrevida associado à ressecção das lesões, aconselha-se um acompanhamento superior a 5 anos.

\section{Bibliografía}

1. Sato K, Takeyama Y, Kato T, Kato T, Hashimoto H, Fukui Y, Gonda H, Suzuki R. Tracheal Adenoid Cystic Carcinoma Treated by Repeated Bronchoscopic Argon Plasma Coagulation as a Palliative Therapy. Ann Thorac Cardiovasc Surg 2014; 20: 602-5.

2. Suemitsu R, Okamoto T, Maruyama R, wataya $H$, Seto T, Ichinose $Y$. Long-Term Survivor after Aggressive Treatment for Tracheal Adenoid Cystic Carcinoma: A Case Report. Ann Thorac Cardiovasc Surg 2007; 13 (5): 335-7.

3. Kukwa W, Korzén P, Wojtowicz P, Sobczyk G, Kiprian D, Kawecki A, Kukwa A, Krzeski A, Szczylik C, Czarnecka A. Tracheal adenoid cystic carcinoma mimicking a thyroid tumor: A case report. Oncology Letters 8, 2014; 1312-16.

4. Caiado A, Moura e Sá J. Revisão dos tumores da traqueia - A propósito de um caso clínico de tumor adenóide cístico. Revista Portuguesa de Pneumologia, 2008; XIV (4): 527-534.

5. Bhattacharyya $\mathrm{N}$. Contemporary staging and prognosis for primary tracheal malignancies: A population-based analysis. Otolaryngol Head Neck Surg 2004; 131:639-42.

6. Suzuki T. What Is the Best Management Strategy for Adenoid Cystic Carcinoma of the Trachea? Ann Thorac Cardiovasc Surg 2011; 15:537-538. 